\title{
Overview of the Korean Longitudinal Study on Cognitive Aging and Dementia
}

\author{
Ji Won Han', Tae Hui Kim², Kyung Phil Kwak3 ${ }^{3}$ Kayoung Kim4, Bong Jo Kim5, Shin Gyeom Kim6, \\ Jeong Lan Kim², Tae Hyun Kim¹, Seok Woo Moon ${ }^{8}$, Jae Young Park', Joon Hyuk Park ${ }^{9}$, Seonjeong Byun', \\ Seung Wan Suh ${ }^{1}$, Ji Young Seo ${ }^{10}$, Yoonseop So ${ }^{1}$, Seung-Ho Ryu ${ }^{11}$, Jong Chul Youn ${ }^{12}$, Kyoung Hwan Lee ${ }^{13}$, \\ Dong Young Lee ${ }^{14,15}$, Dong Woo Lee ${ }^{16}$, Seok Bum Lee ${ }^{17}$, Jung Jae Lee ${ }^{17}$, Ju Ri Lee', Hyeon Jeong', \\ Hyun-Ghang Jeong ${ }^{18}$, Jin Hyeong Jhoo ${ }^{19}$, Kyuhee Han', Jong Woo Hong ${ }^{1}$, and Ki Woong Kim ${ }^{1,15,20 凶}$
}

${ }^{1}$ Department of Neuropsychiatry, Seoul National University Bundang Hospital, Seongnam, Republic of Korea 2Department of Psychiatry, Yonsei University Wonju Severance Christian Hospital, Wonju, Republic of Korea ${ }^{3}$ Department of Psychiatry, Dongguk University Gyeongju Hospital, Gyeongju, Republic of Korea

${ }^{4}$ Department of Psychiatry, National Center for Mental Health, Seoul, Republic of Korea

${ }^{5}$ Department of Psychiatry, Gyeongsang National University School of Medicine, Jinju, Republic of Korea

${ }^{6}$ Department of Neuropsychiatry, Soonchunhyang University Bucheon Hospital, Bucheon, Republic of Korea

${ }^{7}$ Department of Psychiatry, School of Medicine, Chungnam National University, Daejeon, Republic of Korea

${ }^{8}$ Department of Psychiatry, School of Medicine, Konkuk University, Konkuk University Chungju Hospital, Chungju, Republic of Korea

${ }^{9}$ Department of Neuropsychiatry, Jeju National University Hospital, Jeju, Republic of Korea

${ }^{10}$ Department of Neuropsychiatry, Changwon Gyeongsang National University Hospital, Changwon, Republic of Korea

${ }^{11}$ Department of Psychiatry, School of Medicine, Konkuk University, Konkuk University Medical Center, Seoul, Republic of Korea

${ }^{12}$ Department of Neuropsychiatry, Kyunggi Provincial Hospital for the Elderly, Yongin, Republic of Korea

${ }^{13}$ Department of Psychiatry, Bongseng Memorial Hospital, Busan, Republic of Korea

${ }^{14}$ Department of Neuropsychiatry, Seoul National University Hospital, Seoul, Republic of Korea

${ }^{15}$ Department of Psychiatry, Seoul National University College of Medicine, Seoul, Republic of Korea

${ }^{16}$ Department of Neuropsychiatry, Inje University Sanggye Paik Hospital, Seoul, Republic of Korea

${ }^{17}$ Department of Psychiatry, Dankook University Hospital, Cheonan, Republic of Korea

${ }^{18}$ Department of Psychiatry, Korea University Guro Hospital, Korea University College of Medicine, Seoul, Republic of Korea

${ }^{19}$ Department of Psychiatry, Kangwon National University School of Medicine, Chuncheon, Republic of Korea

${ }^{20}$ Department of Brain and Cognitive Science, Seoul National University College of Natural Sciences, Seoul, Republic of Korea

Objective Due to an unprecedented rate of population aging, South Korea is facing a dementia epidemic. For this reason, the Korean Longitudinal Study on Cognitive Aging and Dementia (KLOSCAD) was launched in 2009 with support from the Korean Health Industry Development Institute to investigate the epidemiology, biopsychosocial risk factors, and outcomes of dementia and dementia-related conditions.

Methods The KLOSCAD is the first nationwide multi-center population-based prospective cohort study. In October 2010, 12,694 individuals were randomly sampled from residents aged 60 years or older who lived in 13 districts across South Korea. In the baseline assessment, which was conducted from November 2010 through October 2012, 6,818 (53.7\%) individuals participated. Follow-up assessments have been conducted every two years, with the first follow-up assessment conducted between November 2012 and October 2014, and the second between November 2014 and October 2016. The third is now in progress, and will span from November 2016 to October 2018. Diagnosis of cognitive disorders, neuropsychological battery, behavioral and psychological symptoms of dementia, activities of daily living, physical and neurologic examination and laboratory tests, life styles, quality of life, and identification of death were evaluated in each assessment.

Results The cumulative drop-out rate at the second follow-up assessment was $38.7 \%$. Dementia and mild cognitive impairment were $5.0 \%$ and $27.0 \%$, respectively.

Conclusion The KLOSCAD may provide strong scientific evidence for advancing the fight against dementia both in Korea and globally. Psychiatry Investig 2018;15(8):767-774

Key Words Community, Multicenter, Longitudinal, Prospective, Cohort study, Cognitive ageing, Dementia, Mild cognitive impairment, Korea.

Received: May 1, 2018 Revised: May 18, 2018 Accepted: June 2, 2018

$\triangle$ Correspondence: Ki Woong Kim, MD, PhD Department of Brain and Cognitive Science, Seoul National University College of Natural Sciences, Seoul, Republic of Korea, Department of Neuropsychiatry, Seoul National University College of Medicine and Seoul National University Bundang Hospital, 82 Gumi-ro 173 beon-gil, Bundang-gu, Seongnam 13620, Republic of Korea

Tel: +82-31-787-7432, Fax: +82-31-787-4058, E-mail: kwkimmd@snu.ac.kr

(a) This is an Open Access article distributed under the terms of the Creative Commons Attribution Non-Commercial License (https://creativecommons.org/licenses/by-nc/4.0) which permits unrestricted non-commercial use, distribution, and reproduction in any medium, provided the original work is properly cited. 


\section{INTRODUCTION}

Most dementing illnesses are complex multifactorial diseases that are incurable and require comprehensive and longterm observation. In developed Western countries that became an aged society (at least 14\% of the national population 65 or older defined by the United Nations) earlier than Korea, community-based prospective cohort studies on aging and dementia have been being actively conducted since the early 1990s. In many Asian countries that are rapidly aging, most community-based prospective cohort studies on aging and dementia began after the year 2000. Asians have different genetic backgrounds, environments, and life styles and thus may have different disease epidemiology and dementia risk factors than Caucasians.

In South Korea (hereafter, Korea), the number of dementia patients is rapidly increasing due to an unprecedented rate of population aging. It will take only 25 years for Korea to shift from an aging society into a superaged society. Korea became an aging society in 2000 , and is expected to become an aged society by the end of 2017 , and a superaged society by $2025 .{ }^{1}$ In 2017, the prevalence of dementia among Koreans aged 65 years or older was estimated to be $10.2 \%$, and the number of individuals with dementia to be $724,857 .{ }^{2,3}$ The number of dementia patients will double every 17 years and reach nearly 3 million in 2050., The age-standardized incidence of Alzheimer's disease $(\mathrm{AD})$ and mild cognitive impairment $(\mathrm{MCI})$ is reported to be 7.9 and 28.1 cases per 1,000 person-years, respectively. ${ }^{4}$ The current national dementia cost to Korea is estimated to be approximately 12 billion US dollars (USD), which is approximately $0.9 \%$ of the Korean national gross domestic product (GDP). This cost is expected to double every 10 years and will reach approximately 93 billion USD by 2050 , which will be approximately $3.8 \%$ of the expected Korean national GDP. ${ }^{5}$

The Korean government declared 'A War Against Dementia' in 2008 and has been preparing a National Dementia Plan every five years. The Korean National Assembly unanimously passed the 'Dementia Management Act (DeMA)' in August 2011. Based on the National Dementia Plans, the Korean government began to support a community-based prospective elderly cohort study that aimed to investigate epidemiological estimates, risk factors, preventive measures, and outcomes of dementia. This study, the Korean Longitudinal Study on Cognitive Aging and Dementia (KLOSCAD), is the first multicenter nationwide population-based prospective cohort study for investigating the epidemiology, biopsychosocial risk factors, and outcomes of normal cognitive aging and various dementing illnesses. The study launched in 2009 with support from the Korean Health Industry Development Institute. The four main aims of this study were to: 1) estimate the epidemiology of dementia and related disorders in Korea; 2) explore the diagnostic markers of dementia and establish their normative data in elderly Koreans; 3) propose optimal strategies for preventing and managing dementia in Koreans; and 4) provide evidence for developing cost-effective dementia policies in Korea.

\section{METHODS}

\section{Subjects (Table 1)}

The initial sample size (NS) of the KLOSCAD was estimated to be 6,248 using the following equation:

$\mathrm{NS}=1.96^{2} \mathrm{PQW} /\left[\mathrm{E}^{2}+\left(1.96^{2} \mathrm{PQW} / \mathrm{N}_{\mathrm{T}}\right)\right]$ where $\mathrm{P}$ refers to the expected prevalence (\%) of dementia, Q refers to 100-P (\%), W refers to the expected design effect, $\mathrm{E}$ refers to the maximum acceptable random sampling error (\%), and NT refers to the number of the total population. ${ }^{6} \mathrm{P}$ was assumed to be $8.94 \%$, which was the estimated prevalence of dementia in 2011 based on a previous nationwide survey performed in $2008 .{ }^{3} \mathrm{~W}$ was assumed to be 2 , and $\mathrm{E}$ was set as $1 \%$. The number of Korean individuals aged 65 years old or over in $2011(5,700,972)$ was computed as NT. Assuming a response rate of $50 \%$, we needed to approach 12,496 individuals to obtain our desired sample of 6,248. Assuming a response rate of 50\%, we needed to approach 12,496 individuals to obtain our desired sample of 6,248. In order to construct a representative cohort of elderly Koreans, we randomly sampled 30 villages and towns from 13 districts across South Korea. We then randomly selected $10 \%$ of residents aged 60 years or older in urban areas and $20 \%$ in rural areas using residential rosters on October 2010. Finally, 12,694 elderly individuals were sampled, and 6,818 (53.7\%) participated in the baseline assessment of the KLOSCAD. All participants were fully informed of the study protocol, and provided written informed consent, signed by the subjects or their legal guardians.

\section{Research centers (Figure 1)}

The KLOSCAD is a multi-center study steered by Seoul National University Bundang Hospital (SNUBH). Including SNUBH, 13 research centers across the country participate in the KLOSCAD: 3 in Seoul, 3 in Gyeonggi-do, 1 in Gangwondo, 2 in Chungcheongnam-do, 1 in Chungcheongbuk-do, 1 in Gyeongsangbuk-do, 1 in Gyeongsangnam-do, and 1 in Jejudo. Each center was responsible for evaluating participants from a particular district. All investigators and research staff, including geropsychiatrists, neuropsychologists, and nurses from the 13 research centers, completed 8 hours of protocolbased training and passed 10 case examination tests prior to the baseline assessment. 
Table 1. Demographic and clinical characteristics of the study subjects at baseline, 1st follow-up, and 2nd follow-up

\begin{tabular}{|c|c|c|c|c|}
\hline & Baseline & 1st follow-up & 2nd follow-up & $\mathrm{p}$ value§ \\
\hline Participants, $\mathrm{N}$ & 6,818 & 5,131 & 4,181 & \\
\hline Duration of follow-up, years & - & $2.04 \pm 0.26$ & $3.91 \pm 0.29$ & \\
\hline Age, years & $70.50 \pm 7.10$ & $72.03 \pm 6.64$ & $73.32 \pm 6.32$ & $<0.001$ \\
\hline Women, N (\%) & $3,919(57.5)$ & $2,940(57.3)$ & $2,410(57.6)$ & 0.946 \\
\hline Education, years & $7.83 \pm 5.38$ & $8.23 \pm 5.36$ & $8.42 \pm 5.32$ & $<0.001$ \\
\hline Illiteracy in reading, $\mathrm{N}(\%)$ & $275(4.0)$ & $165(3.2)$ & $109(2.6)$ & $<0.001$ \\
\hline Illiteracy in writing, N (\%) & $323(4.7)$ & $200(3.9)$ & $120(2.9)$ & $<0.001$ \\
\hline History of occupation, N (\%) & $2,035(29.8)$ & $1,550(30.2)$ & $1,160(27.7)$ & 0.007 \\
\hline Marital status, N (\%) & & & & 0.295 \\
\hline Married & $4,697(68.9)$ & $3,531(68.8)$ & $2,851(68.2)$ & \\
\hline Bereaved & $1,789(26.2)$ & $1,401(27.3)$ & $1,169(28.0)$ & \\
\hline Divorced, separated, unmarried & $332(4.9)$ & $199(3.9)$ & $161(4.0)$ & \\
\hline Cohabitants, N (\%) & & & & $<0.001$ \\
\hline None & $1,000(14.7)$ & $839(16.4)$ & $718(17.2)$ & \\
\hline Family & $5,673(83.2)$ & $4,205(82.0)$ & $3,432(82.1)$ & \\
\hline Others & $145(2.13)$ & $67(1.31)$ & $20(0.5)$ & \\
\hline Institutionalized & - & $20(0.4)$ & $11(0.3)$ & \\
\hline Cumulative Illness Rating Scale & $4.50 \pm 2.85$ & $4.88 \pm 2.87$ & $5.53 \pm 3.03$ & $<0.001$ \\
\hline Modified Hachinski Ischemic Scale & $0.84 \pm 1.37$ & $0.90 \pm 1.24$ & $0.87 \pm 1.22$ & 0.069 \\
\hline Geriatric Depression Scale & $10.07 \pm 6.62$ & $9.03 \pm 6.5$ & $9.10 \pm 6.49$ & $<0.001$ \\
\hline Diagnosis, N (\%) & & & & $<0.001^{\| \prime}$ \\
\hline Cognitively normal & $4,572(67.1)$ & $3,625(70.6)$ & $3,062(73.2)$ & \\
\hline Cognitively normal & $2,286(33.5)$ & $1,923(37.5)$ & $1,730(41.4)$ & \\
\hline Subjective Cognitive Impairment* & $1,100(16.1)$ & $898(17.5)$ & $749(17.9)$ & \\
\hline Objective Cognitive Impairment $^{\dagger}$ & $1,186(17.4)$ & $804(15.7)$ & $583(13.9)$ & \\
\hline CIND & $1,903(27.9)$ & $1,266(24.7)$ & $892(21.3)$ & \\
\hline MCI & $1,838(27.0)$ & $1,238(24.1)$ & $875(20.9)$ & \\
\hline Amnestic single domain & $552(8.1)$ & $349(6.8)$ & $273(6.5)$ & \\
\hline Amnestic multiple domain & $769(11.3)$ & $446(8.7)$ & $272(6.5)$ & \\
\hline Nonamnestic single domain & $383(5.6)$ & $372(7.3)$ & $279(6.7)$ & \\
\hline Nonamnestic multiple domain & $134(2.0)$ & $71(1.4)$ & $51(1.2)$ & \\
\hline Other CIND & $65(1.0)$ & $28(0.5)$ & $17(0.4)$ & \\
\hline Dementia & $343(5.0)$ & $240(4.7)$ & $227(5.4)$ & \\
\hline Alzheimer's disease & $244(3.6)$ & $180(3.5)$ & $178(4.3)$ & \\
\hline Vascular dementia & $44(0.6)$ & $25(0.5)$ & $24(0.6)$ & \\
\hline Mixed dementia ${ }^{\ddagger}$ & $15(0.2)$ & $11(0.2)$ & $8(0.2)$ & \\
\hline DLB or PDD & $7(0.1)$ & $8(0.2)$ & $5(0.1)$ & \\
\hline FTLD & $3(0.0)$ & $4(0.1)$ & $0(0.0)$ & \\
\hline Other dementia & $30(0.4)$ & $12(0.2)$ & $12(0.3)$ & \\
\hline
\end{tabular}

*clinical judgment of subjective cognitive impairment, but neuropsychological performance of the subjects was higher than -1.5 SD of age-, gender-, and education-adjusted norms in any of the neuropsychological tests, ${ }^{\dagger}$ no evidence of subjective cognitive impairment, but neuropsychological performance of the subjects was -1.5 SD or below of age-, gender-, and education-adjusted norms in any of neuropsychological tests, ${ }^{\ddagger}$ combined etiology of Alzheimer’s disease and vascular pathology, §derived from one-way analysis of variance for continuous variables, from a chi-square test for categorical variables, "p value between cognitive normal, mild cognitive impairment, and dementia. CIND: cognitive impaired not dementia, MCI: mild cognitive impairment, DLB: dementia with Lewy bodies, PDD: Parkinson's disease with dementia, FTLD: frontotemporal lobar degeneration 


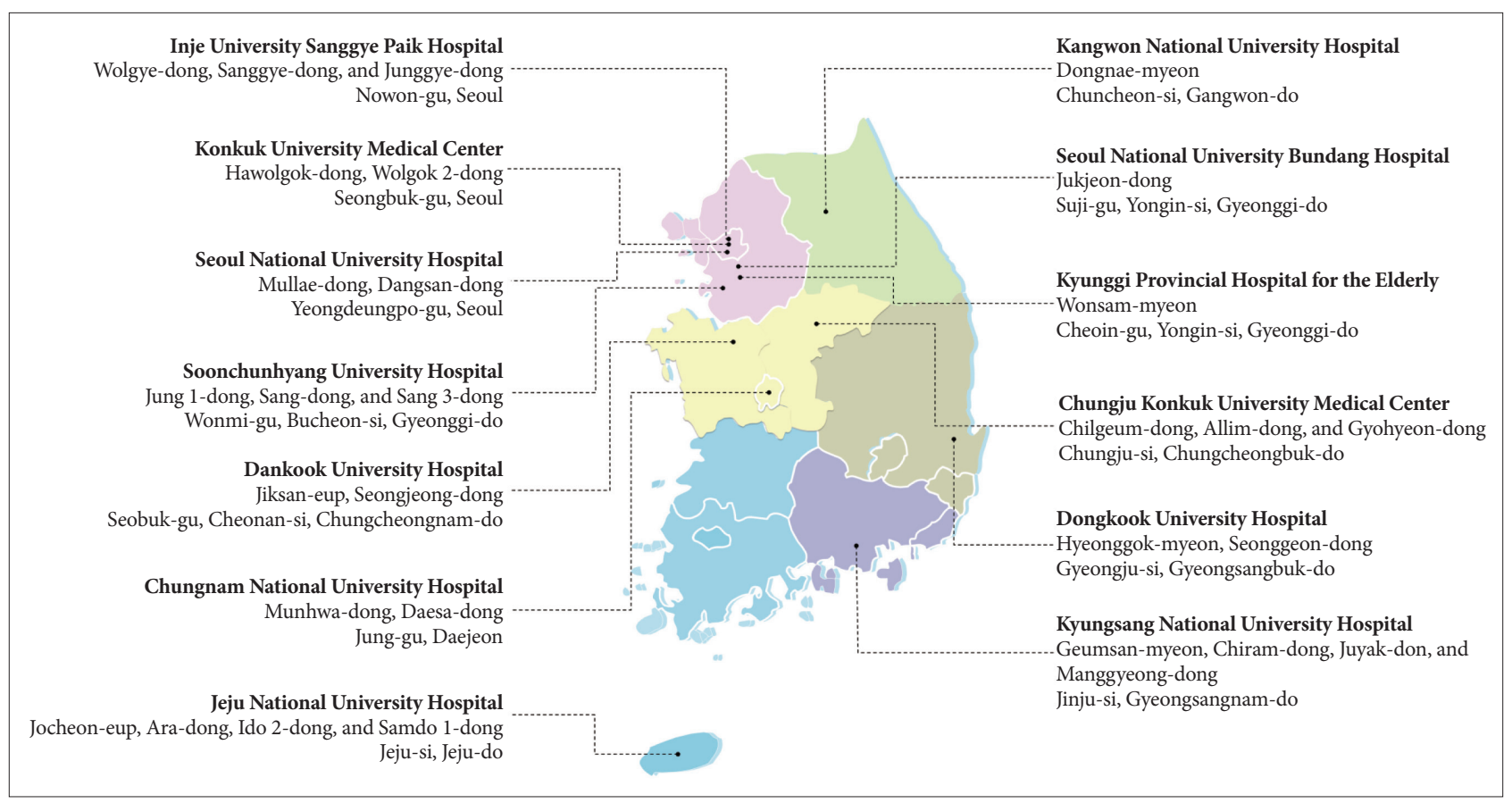

Figure 1. Map of the study centers.

\section{Schedules}

The baseline evaluation was conducted over two years, from November 2010 to October 2012. Follow-up evaluations have been conducted every two years. The first follow-up evaluation was conducted from November 2012 to October 2014, the second from November 2014 to October 2016, and the third (currently in progress) from November 2016 to October 2018. The Institutional Review Board of SNUBH (no. B-0912/089-010), Korea, approved this study protocol.

\section{Assessments}

\section{Diagnostic assessments of cognitive disorders and comorbid conditions}

Geriatric neuropsychiatrists with expertise in dementia research administered a face-to-face standardized diagnostic interview as well as physical and neurological examinations using the Korean version of the Consortium to Establish a Registry for Alzheimer's Disease Assessment Packet (CERAD$\mathrm{K})$ Clinical Assessment Battery (CERAD-K-C $)^{7}$ to diagnose cognitive disorders. Comorbid mental disorders, including depressive disorders, were evaluated using the Korean version of Mini International Neuropsychiatric Interview (MINI$\mathrm{K}),{ }^{8,9}$ and cerebrovascular accidents were evaluated using the Transient Ischemic Attack and Stroke Interview form from the Atherosclerosis Risk In Community study (ARIC). ${ }^{10}$ The Unified Parkinson's Disease Rating Scale (UPDRS) ${ }^{11}$ was administered to the subjects found to be abnormal in Tinetti
Performance Oriented Mobility Assessment (POMA) ${ }^{12}$ and/or the Screening Questionnaire for Parkinson's Disease (PDSQ) ${ }^{13}$ and/or who had a history of movement disorders including Parkinson's disease. Trained research nurses examined the family history of cognitive disorders, cerebrovascular diseases, and Parkinson's disease in first-degree relatives using a study-specific form that included the kinship with the subject and age of onset. Rapid eye movement (REM) sleep behavior disorders, restless legs syndrome, and sleep apnea were screened using the REM Sleep Behavior Disorder Screening Questionnaire (RBDSQ), ${ }^{14}$ Cambridge Hopkins questionnaire for ascertainment of restless legs syndrome (CH RLSq), ${ }^{15}$ and the STOP-Bang questionnaire (STOPQ $)^{16}$ respectively.

\section{Cognitive function assessments}

Trained research nurses administered the Subjective Memory Complaints Questionnaire (SMCQ) ${ }^{17}$ to the subjects and the Korean version of the Short Informant Questionnaire on Cognitive Decline in the Elderly (SIQCODE-K) ${ }^{18}$ to their informants to evaluate subjective complaints associated with cognitive impairment. Research neuropsychologists or trained research nurses administered the Korean version of the Consortium to Establish a Registry for Alzheimer's Disease Assessment Packet (CERAD-K) Neuropsychological Assessment Battery (CERAD-K-N), ${ }^{7,19}$ Digit Span Test (DST), ${ }^{20}$ Executive Clock Drawing Task (CLOX), ${ }^{21,22}$ Frontal Assessment Battery, ${ }^{23}$ and Severe Cognitive Impairment Rating Scale (SCIRS) ${ }^{24}$ to each subject. The CERAD-K-N consists of nine neuropsycho- 
logical tests: Verbal Fluency Test, 15-item Boston Naming Test, Mini Mental Status Examination, Word List Memory Test, Constructional Praxis Test, Word List Recall Test, Word List Recognition Test, Constructional Recall Test, and Trail Making Test $\mathrm{A} / \mathrm{B} .{ }^{7,19}$

\section{Behavioral and psychological symptoms of dementia assessments}

Trained research nurses evaluated behavioral and psychological symptoms of dementia (BPSD) using the Korean version of the Geriatric Depression Scale (GDS-K), ${ }^{24}$ the Korean version of the Neuropsychiatric Inventory (NPI-K), ${ }^{25}$ the Korean version of Dysexecutive Questionnaire (DEX-K), ${ }^{26,27}$ and the Sleep Disorder Inventory (SDI-K). ${ }^{28}$

\section{Activities of daily living assessments}

Trained research nurses evaluated the basic and instrumental activities of daily living (ADL) using the Disability Assessment for Dementia (DAD), ${ }^{29,30}$ and the level of dependency using Dependence Scale (DS). ${ }^{31,32}$

\section{Physical and neurologic examination and laboratory tests}

Geriatric neuropsychiatrists conducted routine physical and neurologic examinations. They evaluated gait and balance using the Tinetti Performance Oriented Mobility Assessment (POMA). ${ }^{12}$ Research nurses checked vital signs (blood pressure, heart rate, and respiration rate), and measured height, weight, and head, neck, waist, and hip circumferences. They evaluated all medications that the subjects were taking or had taken within six weeks using a study-specific assessment form, and the burden of comorbid illnesses using the Cumulative Illness Rating Scale (CIRS). ${ }^{33}$ They also evaluated handedness using the Edinburgh Handedness Inventory. ${ }^{34}$ Complete blood cell counts, chemistry profiles, a rapid plasma reagin (RPR) test for screening syphilis, a thyroid function test (free $\mathrm{T} 4$, thyroid stimulating hormone), and vitamin B12, folate, and apolipoprotein E (APOE) genotyping were administered to all subjects. Additionally, brain magnetic resonance imaging [T1-weighted, T2-weighted, and Fluid-attenuated inversion recovery (FLAIR)] was performed on the subjects who were diagnosed with dementia.

\section{Life styles}

Trained research nurses evaluated socio-demographic information, social activities, and occupational history using studyspecific assessment forms in face-to-face interviews, and evaluated the risk of driving using the Driving Risk Questionnaire (DRQ). ${ }^{35}$ They evaluated the use of nutritional supplements and beverages using study-specific assessment forms in faceto-face interviews, at-risk drinking using the Korean version of Alcohol Use Disorders Identification Test (AUDIT-K), ${ }^{36,37}$ and nicotine dependence using the Korean version of the Fagerstrom Test for Nicotine Dependence (FTND-K) ${ }^{38,39}$ Additionally, they also evaluated sleep habit and quality using the Korean version of the Pittsburgh Sleep Quality Index (PSQI). ${ }^{40}$

\section{Quality of life}

Trained research nurses evaluated QoL using the EuroQol (EQ)-5D $\mathrm{D}^{41}$ and the Quality of Life-Alzheimer's disease (QoL$\mathrm{AD}){ }^{42,43}$ and the level of perceived social support using the Medical Outcomes Study Social Support Survey. ${ }^{44}$

\section{Identification of death}

We identified the deaths of subjects annually from the $\mathrm{Na}$ tional Mortality Database of Statistics Korea.

\section{Diagnosis}

A panel of research neuropsychiatrists determined the final diagnoses and the Clinical Dementia Rating $(\mathrm{CDR}) .{ }^{45}$ They diagnosed dementia according to the Diagnostic and Statistical Manual of Mental Disorders, Fourth Edition (DSM-IV) diagnostic criteria. ${ }^{46}$ They determined the subtypes of dementia according to the following diagnostic criteria: $\mathrm{AD}$ according to the criteria of the National Institute of Neurological and Communicative Disorders and Stroke and the Alzheimer's Disease and Related Disorders Association, ${ }^{47}$ vascular dementia $(\mathrm{VaD})$ according to the criteria of the National Institute of Neurological Disorders and Stroke-Association Internationale pour la Recherche et l'Enseigne-menten Neurosciences, ${ }^{48}$ dementia with Lewy bodies (DLB) and Parkinson's disease with dementia (PDD) according to the consensus guideline proposed by McKeith et al., ${ }^{49}$ frontotemporal lobar degeneration (FTLD) according to the Neary criteria, ${ }^{50}$ and alcohol-related dementia (ARD) according to the diagnostic criteria proposed by Oslin et al..$^{51} \mathrm{MCI}$ was diagnosed according to the Consensus Criteria from the International Working Group on $\mathrm{MCI}^{52}$ The presence of objective cognitive impairment was ascertained when the performance of the subjects was -1.5 standard deviations (SD) or below the age-, gender-, and education-adjusted norms in any of neuropsychological tests.

Major depressive disorder (MDD) was diagnosed according to the DSM-IV criteria, and minor depressive disorder (MnDD) according to research criteria proposed in Appendix B of the DSM-IV criteria. Subsyndromal depression (SSD) was defined according to the following study-specific operational criteria: 1) the presence of two or more concurrent symptoms of depression by the DSM-IV with at least one being a core depressive symptom such as depressed mood or loss of interest, 2) the presence of each symptom for 'more than half of every day' or 'more than seven days during two weeks', 3) evidence of so- 
cial and occupational dysfunction, and 4) does not meet the criteria for the diagnosis of MDD or MnDD.

\section{Analysis}

The research geropsychiatrists and research statisticians estimated the age group (60-65 years old, 65-69 years old, 7074 years old, 75-79 years old, 80 years old or over) and gender-specific prevalence and incidence. For each estimate, 95\% confidence intervals (CI) were derived using the exact binomial method. Standardized prevalence and incidence rates of elderly Koreans were estimated using the direct standardization method, in which age, gender, and education were adjusted using data from the 2010 National Census of Korea. Risk factors were explored using logistical regression analysis, cox proportional hazard analysis, or path analysis. Survival and institutionalization were estimated using the KaplanMeier survival analysis.

\section{RESULTS}

\section{Progress of the Study}

\section{Response rate}

The cumulative drop-out rate at the second follow-up as- sessment was $38.7 \%$. In the first follow-up assessment, 1,494 did not respond ('Lost' in Figure 2); 1,170 refused to participate, 50 were institutionalized, 56 were too unwell to participate, and 218 moved or changed their contact information. In the second follow-up assessment, 2,178 did not respond ('Lost' in Figure 2); 1,263 refused to participate, 89 were institutionalized, 37 were too unwell to participate, and 789 moved or changed their contact information.

The demographic and clinical characteristics of the subjects in the baseline, first follow-up, and second follow-up assessments are summarized in Table 1 . The subjects in the follow-up evaluations were older, more educated, and had lower depression scale scores. The CIRS scores that indicate the cumulative burden of comorbid diseases increased with the aging of the cohort. With an increase in the number of follow-up assessments, the proportion of cognitively normal participants increased $(67.1 \%$ at baseline, $70.6 \%$ at 1 st followup, $73.2 \%$ at 2 nd follow-up).

\section{International collaboration}

The KLOSCAD participates in the development of the Cohort Studies of Memory in an International Consortium (COSMIC), ${ }^{53}$ and has contributed to various collaborative research projects on cognitive disorders. ${ }^{54,55}$ The KLOSCAD is

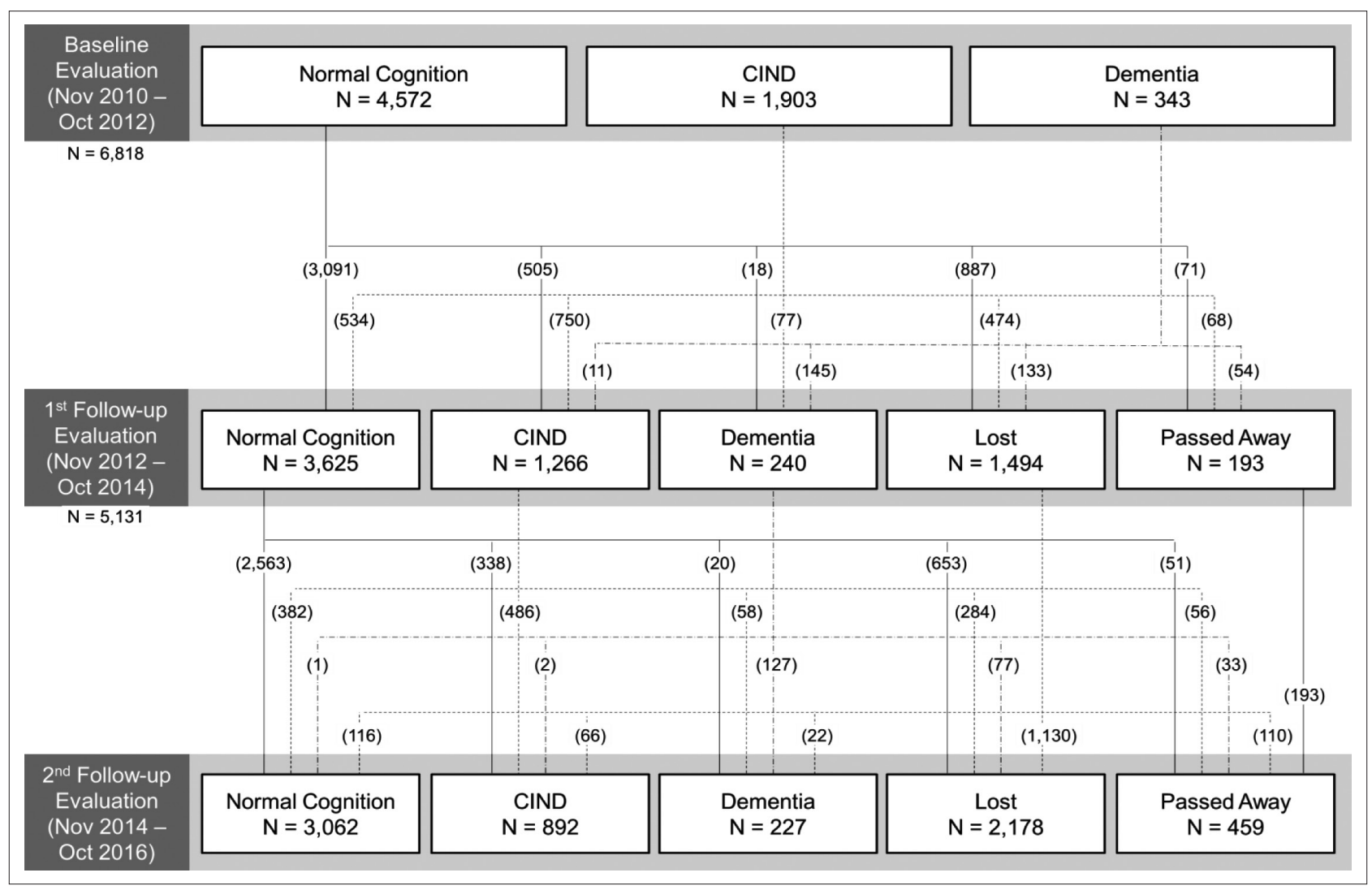

Figure 2. Flow diagram of the Korean Longitudinal Study on Cognitive Aging and Dementia (KLOSCAD). CIND: cognitive impairment not dementia. 
one of the contributors of the International Neuropsychological Normative Database Initiative (INNDI), which aims to develop regression-based norms that enable users to adjust cognitive test scores for a test taker's age, sex, education, country of origin, and language. ${ }^{56}$ The KLOSCAD has also contributed to the Global Alzheimer's Association Interactive Network (GAAIN), which is an operational online integrated research platform of global networks of Alzheimer's disease study centers. ${ }^{57}$

\section{DISCUSSION}

The KLOSCAD is the first multi-center nationwide population-based prospective cohort study on cognitive aging and dementia in Korea. Since we expect that more than 3,000 subjects will respond to the third follow-up assessment, we are preparing to extend this study until 2024. Attrition based on the disproportionate loss of subjects presenting cognitive decline over time might lead to biased estimates of longitudinal outcomes. Among the baseline diagnosis, 34.3\% of cognitive normal, $43.1 \%$ of MCI, and $71.7 \%$ of dementia were lost to the 2nd follow-up assessment. We will investigate attrition and reflect it in the design and analysis of specific hypotheses. ${ }^{58}$ The KLOSCAD will not only provide epidemiological data of dementia and related disorders, but also find the various diagnostic and predictive markers for dementia using data from comprehensive assessments. We believe this study will provide strong scientific evidence for advancing the fight against dementia, both in Korea and globally.

\section{Acknowledgments}

This study was supported by a grant from the Korean Health Technology R\&D Project, Ministry of Health and Welfare, Republic of Korea [grant no. HI09C1379 (A092077)].

\section{REFERENCES}

1. Korean National Statistical Office. Population Projections for Korea. Available at: http://kosis.kr/statHtml/statHtml.do?orgId=101\&tblid=D T_1BPB003\&conn_path=I2. Accessed June 22, 2017.

2. Ministry of Health \& Welfare. 2012 National Study on the Prevalence of Dementia in Korean Elders. Ministry of Health \& Welfare, Korea; 2012.

3. Kim KW, Park JH, Kim MH, Kim MD, Kim BJ, Kim SK, et al. A nationwide survey on the prevalence of dementia and mild cognitive impairment in South Korea. J Alzheimers Dis 2011;23:281-291.

4. Bae JB, Kim YJ, Han JW, Kim TH, Park JH, Lee SB, et al. Incidence of and risk factors for Alzheimer's disease and mild cognitive impairment in Korean elderly. Dement Geriatr Cogn Disord 2015;39:105-115.

5. Natioanl Institute of Dementia. Korean Dementia Observatory 2016. Seongnam: Natioanl Institute of Dementia, Korea; 2016.

6. Cochran WG. Sampling Techniques. 3rd Ed. New York: Wiley; 1977.

7. Lee JH, Lee KU, Lee DY, Kim KW, Jhoo JH, Kim JH, et al. Development of the Korean version of the Consortium to Establish a Registry for Alzheimer's Disease Assessment Packet (CERAD-K): clinical and neuropsychological assessment batteries. J Gerontol B Psychol Sci Soc Sci 2002;57:P47-P53.
8. Sheehan DV, Lecrubier Y, Sheehan KH, Amorim P, Janavs J, Weiller E, et al. The Mini-International Neuropsychiatric Interview (M.I.N.I.): the development and validation of a structured diagnostic psychiatric interview for DSM-IV and ICD-10. J Clin Psychiatry 1998;59 (Suppl 20):22-33;quiz 34-57.

9. Yoo SW, Kim YS, Noh JS, Oh KS, Kim CH, Namkoong K, et al. Validity of Korean version of the mini-international neuropsychiatric interview. Anxiety Mood 2006;2:50-55.

10. Atherosclerosis Risk in Communities. TIA/Stroke Forms. Available at: http://www.cscc.unc.edu/aric/manuforms/. Accessed June 22, 2017.

11. Stebbins GT, Goetz CG. Factor structure of the Unified Parkinson's disease rating scale: motor examination section. Mov Disord 1998;13: 633-636.

12. Tinetti ME. Performance-oriented assessment of mobility problems in elderly patients. J Am Geriatr Soc 1986;34:119-126.

13. Kim JH, Cheong HK, Lee CS, Yi SE, Park KW. The validity and reliability of a screening questionnaire for Parkinson's disease in a community. J Prev Med Public Health 2010;43:9-17.

14. Stiasny-Kolster K, Mayer G, Schafer S, Moller JC, Heinzel-Gutenbrunner M, Oertel WH. The REM sleep behavior disorder screening questionnaire--a new diagnostic instrument. Mov Disord 2007;22:23862393.

15. Allen RP, Burchell BJ, MacDonald B, Hening WA, Earley CJ. Validation of the self-completed Cambridge-Hopkins questionnaire $(\mathrm{CH}-$ RLSq) for ascertainment of restless legs syndrome (RLS) in a population survey. Sleep Med 2009;10:1097-1100.

16. Chung F, Yegneswaran B, Liao P, Chung SA, Vairavanathan S, Islam S, et al. STOP questionnaire: a tool to screen patients for obstructive sleep apnea. Anesthesiology 2008;108:812-821.

17. Youn JC, Kim KW, Lee DY, Jhoo JH, Lee SB, Park JH, et al. Development of the subjective memory complaints questionnaire. Dement Geriatr Cogn Disord 2009;27:310-317.

18. Lee DW, Lee J, Ryu SG, Cho SJ, Hong CH, Lee JH, et al. Validity of the Korean Version of Informant Questionnaire on the Cognitive Decline in the Elderly (IQCODE). J Korean Geriatr Soc 2005;9:196-202.

19. Lee DY, Lee KU, Lee JH, Kim KW, Jhoo JH, Kim SY, et al. A normative study of the CERAD neuropsychological assessment battery in the Korean elderly. J Int Neuropsychol Soc 2004;10:72-81.

20. Wechsler D. Wechsler Memory Scale-Revised. New York: Psychological Corporation; 1987.

21. Royall DR, Cordes JA, Polk M. CLOX: an executive clock drawing task. J Neurol Neurosurg Psychiatry 1998;64:588-594.

22. Kim SG, Lee DY, Seo EH, Choo IH, Kim JW, Do YJ, et al. A normative study of an executive Clock Drawing Task (CLOX) in Korean elderly. J Korean Neuropsychiatr Assoc 2009;48:437-446.

23. Kim TH, Huh Y, Choe JY, Jeong JW, Park JH, Lee SB, et al. Korean version of frontal assessment battery: psychometric properties and normative data. Dement Geriatr Cogn Disord 2010;29:363-370.

24. Choe JY, Youn JC, Park JH, Park IS, Jeong JW, Lee WH, et al. The Severe Cognitive Impairment Rating Scale--an instrument for the assessment of cognition in moderate to severe dementia patients. Dement Geriatr Cogn Disord 2008;25:321-328.

25. Cummings JL, Mega M, Gray K, Rosenberg-Thompson S, Carusi DA, Gornbein J. The neuropsychiatric inventory: comprehensive assessment of psychopathology in dementia. Neurology 1994;44:2308-2314.

26. Wilson B, Alderman N, Burgess PW, Emslie H, Evans JJ. Behavioral Assessment of the Dysexecutive Syndrome (BADS). England: Thames Valley Test Company; 1996.

27. Kim H. Kim's Frontal-Executive Function Neuropsychological Test: Commentary. Daegu, Korea: Neuropsy; 2001.

28. Tractenberg RE, Singer CM, Cummings JL, Thal LJ. The Sleep Disorders Inventory: an instrument for studies of sleep disturbance in persons with Alzheimer's disease. J Sleep Res 2003;12:331-337.

29. Gelinas I, Gauthier L, McIntyre M, Gauthier S. Development of a functional measure for persons with Alzheimer's disease: the disability as- 
sessment for dementia. Am J Occup Ther 1999;53:471-481.

30. Suh GH. Development of the Korean version of Disability Assessment for Dementia Scale (DAD-K) to assess function in dementia. J Korean Geriatr Soc 2003;7:278-287.

31. Stern Y, Albert SM, Sano M, Richards M, Miller L, Folstein M, et al. Assessing patient dependence in Alzheimer's disease. J Gerontol 1994; 49:M216-M222.

32. Brickman AM, Riba A, Bell K, Marder K, Albert M, Brandt J, et al. Longitudinal assessment of patient dependence in Alzheimer disease. Arch Neurol 2002;59:1304-1308.

33. Miller MD, Paradis CF, Houck PR, Mazumdar S, Stack JA, Rifai AH, et al. Rating chronic medical illness burden in geropsychiatric practice and research: application of the Cumulative Illness Rating Scale. Psychiatry Res 1992;41:237-248.

34. Oldfield RC. The assessment and analysis of handedness: the Edinburgh inventory. Neuropsychologia 1971;9:97-113.

35. Iverson DJ, Gronseth GS, Reger MA, Classen S, Dubinsky RM, Rizzo $\mathrm{M}$, et al. Practice parameter update: evaluation and management of driving risk in dementia: report of the Quality Standards Subcommittee of the American Academy of Neurology. Neurology 2010;74:1316-1324.

36. Saunders JB, Aasland OG, Babor TF, de la Fuente JR, Grant M. Development of the Alcohol Use Disorders Identification Test (AUDIT): WHO collaborative project on early detection of persons with harmful alcohol consumption--II. Addiction 1993;88:791-804.

37. Kim JS, Oh MK, Park BK, Lee MK, Kim GJ. Screening criteria of alcoholism by Alcohol Use Disorders Identification Test (AUDIT) in Korea. J Korean Acad Fam Med 1999;20:1152-1159.

38. Heatherton TF, Kozlowski LT, Frecker RC, Fagerstrom KO. The Fagerstrom test for nicotine dependence: a revision of the Fagerstrom Tolerance Questionnaire. Br J Addict 1991;86:1119-1127.

39. Ahn HK, Lee HJ, Jung DS, Lee SY, Kim SW, Kang JH. The reliability and validity of Korean version of questionnaire for nicotine dependence. Korean J Fam Med 2002;23:999-1008.

40. Buysse DJ, Reynolds CF 3rd, Monk TH, Berman SR, Kupfer DJ. The Pittsburgh Sleep Quality Index: a new instrument for psychiatric practice and research. Psychiatry Res 1989;28:193-213.

41. EuroQol Group. EuroQol--a new facility for the measurement of healthrelated quality of life. Health Policy 1990;16:199-208.

42. Logsdon RG, Gibbons LE, McCurry SM, Teri L. Quality of life in alzheimer's disease: patient and caregiver reports. J Ment Health Aging 1999;5:21-32.

43. Shin HY. A preliminary study on the Korean version of quality of lifeAlzheimer's disease (QOL-AD) scale in community-dwelling elderly with dementia. J Prev Med Public Health 2006;39:243-248.

44. Sherbourne CD, Stewart AL. The MOS social support survey. Soc Sci Med 1991;32:705-714.
45. Hughes CP, Berg L, Danziger WL, Coben LA, Martin RL. A new clinical scale for the staging of dementia. Br J Psychiatry 1982;140:566-572.

46. American Psychiatric Association. Diagnostic and Statistical Manual of Mental Disorders, Fourth Ed. Washington, DC: American Psychiatric Publishing; 1994.

47. McKhann G, Drachman D, Folstein M, Katzman R, Price D, Stadlan EM. Clinical diagnosis of alzheimer's disease: report of the NINCDSADRDA work group under the auspices of Department of Health and Human Services Task Force on alzheimer's disease. Neurology 1984; 34:939-944.

48. Román GC, Tatemichi TK, Erkinjuntti T, Cummings JL, Masdeu J, Garcia Ja, et al. Vascular dementia diagnostic criteria for research studies: report of the NINDS-AIREN international workshop. Neurology 1993; 43:250.

49. McKeith IG, Galasko D, Kosaka K, Perry EK, Dickson DW, Hansen LA, et al. Consensus guidelines for the clinical and pathologic diagnosis of dementia with Lewy bodies (DLB): report of the consortium on DLB international workshop. Neurology 1996;47:1113-1124.

50. Neary D, Snowden JS, Gustafson L, Passant U, Stuss D, Black Sa, et al. Frontotemporal lobar degeneration A consensus on clinical diagnostic criteria. Neurology 1998;51:1546-1554.

51. Oslin D, Atkinson RM, Smith DM, Hendrie H. Alcohol related dementia: proposed clinical criteria. Int J Geriatr Psychiatry 1998;13:203-212.

52. Petersen RC. Mild cognitive impairment as a diagnostic entity. J Intern Med 2004;256:183-194.

53. Sachdev PS, Lipnicki DM, Kochan NA, Crawford JD, Rockwood K, Xiao S, et al. COSMIC (Cohort Studies of Memory in an International Consortium): an international consortium to identify risk and protective factors and biomarkers of cognitive ageing and dementia in diverse ethnic and sociocultural groups. BMC Neurol 2013;13:165.

54. Sachdev PS, Lipnicki DM, Kochan NA, Crawford JD, Thalamuthu A, Andrews $\mathrm{G}$, et al. The prevalence of mild cognitive impairment in diverse geographical and ethnocultural regions: the COSMIC collaboration. PLoS One 2015;10:e0142388.

55. Lipnicki DM, Crawford JD, Dutta R, Thalamuthu A, Kochan NA, Andrews $\mathrm{G}$, et al. Age-related cognitive decline and associations with sex, education and apolipoprotein E genotype across ethnocultural groups and geographic regions: a collaborative cohort study. PLoS Med 2017; 14:e1002261.

56. International Neuropsychological Normative Database Initiative. Available at: http://inndi.org/. Accessed June 22, 2017.

57. Global Alzheimer's Association Interactive Network (GAAIN). Available at: http://www.gaain.org/. Accessed June 22, 2017.

58. Matthews FE, Chatfield M, Freeman C, McCracken C, Brayne C; MRC CFAS. Attrition and bias in the MRC cognitive function and ageing study: an epidemiological investigation. BMC Public Health 2004;4:12. 